\title{
OS ATAQUES À EDUCAÇÃO PROFISSIONAL NA ATUALIDADE
}

\section{The attacks that professional education at today}

\author{
Nívia Barreto dos Anjos \\ (Instituto Federal de Educação Ciência e Tecnologia \\ Baiano, Santa Inês, Bahia) \\ ORCID iD https://orcid.org/0000-0002-4225-9868
}

\section{Informações do artigo}

Recebido em 31/03/2020

Aceito em 29/04/2020

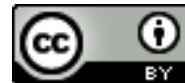

Esta obra está licenciada com uma Licença Creative Commons Atribuição 4.0 Internacional.

\section{Como ser citado (modelo ABNT)}

ANJOS, Nívia Barreto dos. Os ataques à educação profissional na atualidade. Cadernos do CEAS: Revista Crítica de Humanidades. Salvador, v. 45, n. 249, p. 186203, jan./abr. 2020. DOI: https://doi.org/10.25247/2447861X.2020.n249.p186-203

\begin{abstract}
Resumo
Este artigo retrata os ataques que a Educação Profissional enfrenta na atualidade. Seu objetivo geral é demonstrar que a Rede Federal de Educação Profissional, por protagonizar um projeto político pedagógico inovador, incomoda certos atores da hegemonia capitalista e por isso é alvo de ataques nos tempos atuais. Indica que a Rede IF aponta para o desenvolvimento da ciência, da educação, da cultura e do pensamento crítico; sinaliza a intenção do neoliberalismo em "colocar em xeque" a existência e a funcionalidade dos Institutos Federais como espaços de produção e socialização do conhecimento. Reafirma a Política de Educação Profissional como um direito social que precisa ser fortalecido para enfrentar os ditames e a brutalidade do capital, direito este fruto de muitas lutas sociais, e que hoje incomoda aos detentores do capital, por sinalizar uma cidadania crítica e uma educação socialmente referenciada.
\end{abstract}

Palavras-chave: Educação Profissional. Institutos Federais. Capitalismo.

\section{Abstract}

This article portrays the attacks that Professional Education faces today. Its general objective is to demonstrate that the Federal Network of Professional Education, for carrying out an innovative pedagogical political project, bothers certain actors of the capitalist hegemony and for that reason it is the target of attacks in the current times. It indicates that the IF Network points to the development of science, education, culture and critical thinking; also indicates the intention of neoliberalism to "put in check" the existence and functionality of Federal Institutes as spaces for the production and socialization of knowledge. This article reaffirms the Professional Education Policy as a social right that needs to be strengthened to face the dictates and the brutality of capital, a right that is the result of many social struggles. And today this right bothers capital holders, for suport critical citizenship and socially referenced education.

Keywords: Professional Education. Federal Institutes. Capitalism. 


\section{Introdução}

Este artigo busca demonstrar que a Rede Federal de Educação Profissional, por protagonizar um projeto político pedagógico inovador, incomoda certos atores da hegemonia capitalista e por isso é alvo de ataques na atualidade. Desdobrando esse objetivo, procura indicar que a Rede IF representa a difusão da ciência, da educação, da cultura e do pensamento crítico, e sinalizar a intenção do capitalismo em "colocar em xeque" a existência e a funcionalidade dos Institutos Federais como espaços de produção e socialização do conhecimento.

Após a conclusão do Mestrado, estimulada pela convivência intelectual com colegas, professores e examinadores, surgiu na autora o seguinte questionamento: A Educação Profissional seria alvo de ataques, na atualidade, por representar um projeto de excelência para o ensino público, por ser espaço de produção e socialização do conhecimento crítico? Este artigo é uma tentativa preliminar de responder a esta questão. Para isso, levanta-se a seguinte hipótese: A Educação Profissional representa a busca pela excelência no desenvolvimento da ciência e do ensino, e por isto sua existência e funcionalidade são "colocadas em xeque" pelos agentes do capitalismo financeiro num contexto histórico de crise sistêmica do capital?

Para desincumbir-se dessa missão, algumas leituras específicas foram fundamentais. Desde já, são citados, dentre vários estudiosos, Evilásio Salvador no livro "Crise do Capital e Fundo Público: Implicações para o trabalho, os direitos e a política social" (2019) e Eliezer Pacheco em "Institutos Federais: Uma Revolução na Educação Profissional e Tecnológica" (2011). Como, também, vários autores que participaram do "E-Book do I Seminário Internacional de Serviço Social na Educação" (2019), organizado pelos professores Ney Luiz Teixeira de Almeida e Eliana Bolorino, que apresenta riquíssimas contribuições e experiências de trabalhos na Educação e na Educação Profissional.

Convém lembrar que, segundo Triviños (1987, p. 100), cujas dicas metodológicas estão sendo seguidas, a seleção do material bibliográfico a que o pesquisador tem acesso possibilitará analisar até onde outros estudiosos "têm chegado em seus esforços, os métodos empregados, as dificuldades que tiverem de enfrentar, o que pode ainda ser investigado etc."

Quanto ao desenvolvimento do artigo, inicialmente será discutida a Rede IF como representação do desenvolvimento da ciência, da educação, da cultura e do pensamento 
crítico; em seguida, serão analisados o movimento do capitalismo em "colocar em xeque" e a existência e funcionalidade dos Institutos Federais como espaços de produção e socialização do conhecimento. Neste ponto a análise se subdividirá em duas direções: O capitalismo: seus estágios e sua especificidade na sociedade brasileira; A educação como política pública, espaço de socialização, que incomoda o capitalismo por formar cidadãos críticos.

A abordagem teórico-política baseia-se na concepção de Política de Educação Profissional como um direito social que precisa ser fortalecido para enfrentar os ditames e a brutalidade do capitalismo. Direito este, fruto de muitas lutas e contradições do próprio sistema. Uma educação que foi criada para os pobres, mas que, por ações dos seus agentes históricos, nunca se permitiu ser pobre! E que incomoda demais aos detentores do capital, por apresentar uma proposta que, em muitas situações, direciona o estudante a ser um cidadão crítico.

Por esse caminho, o artigo propõe que a Educação Profissional trilhe, a cada dia, o solo concreto das lutas sociais, por meio de dois verbos fundamentais nesse momento: resistir e insistir. Apresenta a concepção de que resistir é mobilizar o pensamento crítico, construtivo e criativo; insistir é acreditar que este pensamento, construtivo e criativo, será capaz de enfrentar os ditames do capitalismo na contemporaneidade.

\section{A Rede IF como representação do desenvolvimento da ciência, da educação, da cultura e pensamento crítico}

A Rede IF - Rede Federal de Educação Profissional, Científica e Tecnológica é originária, em parte, das dezenove Escolas de Aprendizes Artífices criadas em 1909, pelo então Presidente da República Nilo Peçanha, por meio do Decreto n. 7566, de 23 de setembro de 1909. É patente que, no Brasil, a educação tecnológica surgiu como meio de promover o acesso ao mercado de trabalho de pessoas provenientes de famílias em situação de vulnerabilidade, como, também, de enfrentar a ociosidade destes cidadãos (ANJOS, 2020, p. 4).

De acordo com Vidor et al (2011), essas escolas, que de início estavam ligadas ao Ministério dos Negócios da Agricultura, Indústria e Comércio, em 1930, passaram a pertencer ao Ministério da Educação e Saúde Pública. Em 1937, foram transformadas em liceus 
industriais. Em 1942, os liceus receberam a nomenclatura de escolas industriais e técnicas, e em 1959, escolas técnicas federais.

Ao longo deste período vai se constituindo uma rede de escolas agrícolas - Escolas Agrotécnicas Federais -, com base no modelo de escola fazenda e vinculadas ao Ministério da Agricultura. Em 1967, essas escolas-fazenda passam para o então Ministério da Educação e Cultura, tornando-se escolas agrícolas. (VIDOR et al, 2011, p. 48).

Vidor e et al, acrescentam, ainda, que, em 1978, as escolas federais do Rio de Janeiro, Minas Gerais e Paraná foram transformadas em Centros Federais, equiparando-se aos centros universitários. E, durante a década de 1990, várias outras escolas técnicas e agrotécnicas transformaram-se em Cefets.

Em 2008, por meio da Lei no 11.892, de 29 de dezembro, foi instituída a Rede Federal de Educação Profissional, Científica e Tecnológica e criados os Institutos Federais de Educação, Ciência e Tecnologia.

A proposta dos Institutos Federais entende a educação como instrumento de transformação e de enriquecimento do conhecimento, capaz de modificar a vida social e atribuir maior sentido e alcance ao conjunto da experiência humana [...]. Os Institutos Federais tornam-se espaço privilegiado para a democratização do conhecimento científico e tecnológico e valorização do conhecimento popular. (VIDOR et al, 2011, p. 52).

Corroborando com este pensamento, Pacheco, ao se reportar aos Institutos Federais, registra que a educação necessita aproximar-se de um projeto que almeje a construção de uma nova sociedade, fundada na igualdade política, econômica e social: "essa sociedade em construção exige uma escola ligada ao mundo do trabalho numa perspectiva radicalmente democrática e de justiça social" (PACHECO, 2011, p. 8).

Entretanto, não basta incluir em uma sociedade desigual, reprodutora de desigualdade. O conceito de inclusão tem de estar vinculado ao de emancipação, quando se constrói os princípios básicos da cidadania como consciência, organização e mobilização. Ou seja, a transformação do educando em sujeito da história. (PACHECO, 2011, p. 10)

Partindo desta concepção, Caldas (2011) ressalta que a estruturação curricular da Educação Profissional busca articular teoria e prática, o científico e o tecnológico, com conhecimentos que levem o estudante a atuar no mundo em constante mudança, buscando a autonomia e desenvolvendo o espírito crítico e investigativo.

E Pacheco (2011, p. 11) vai além ao afirmar: 
Nosso objetivo central não é formar um profissional para o mercado, mas sim um cidadão para o mundo do trabalho - um cidadão que tanto poderia ser um técnico quanto um filósofo, ou escritor ou tudo isso. Significa superar o conceito de classe de que um trabalhador não pode ser um intelectual, um artista.

Neste sentido, o autor destaca que os Institutos Federais de Educação, Ciência e Tecnologia representam a condensação daquilo que de melhor a Rede Federal construiu ao longo da sua história. "São caracterizados pela ousadia e inovação necessárias a uma política e a um conceito que pretendem antecipar aqui e agora as bases de uma escola contemporânea do futuro e comprometida com uma sociedade radicalmente democrática e socialmente justa" (PACHECO, 2011, p. 12).

De acordo com o artigo $6^{\circ}$ da Lei $n^{\circ} 11.892$, de 29 de dezembro de 2008, as finalidades e características dos Institutos Federais são nove, porém dentro da especificidade deste artigo serão destacadas três:

I. Ofertar educação profissional e tecnológica, em todos os seus níveis e modalidades, formando e qualificando cidadãos com vistas na atuação profissional nos diversos setores da economia, com ênfase no desenvolvimento socioeconômico local, regional e nacional; II. Desenvolver a educação profissional e tecnológica como processo educativo e investigativo de geração e adaptação de soluções técnicas e tecnológicas às demandas sociais e peculiaridades regionais; IV. Constituir-se em centro de excelência na oferta do ensino de ciências, em geral, e de ciências aplicadas em particular, estimulando o desenvolvimento do espírito crítico, voltado à investigação empírica. (BRASIL, 2008, art. 60, grifo nosso).

Este projeto de constituir a educação profissional como centro de excelência incomoda os detentores do capital porque eles não almejam formar cidadãos críticos e que estudem em uma instituição que oferte uma educação de qualidade. Eles objetivam, sim, a constituição de estudantes acríticos, adestrados e que não tenham interesse na investigação empírica.

Voltando a Vidor et al (2011), o objetivo primeiro dos Institutos Federais sempre foi a profissionalização, e, por esta razão, a sua proposta pedagógica possui a compreensão do trabalho como atividade criativa fundamental da vida humana e, como forma histórica, a produção.

Neste sentido Pacheco (2011, p. 14) salienta: 
Na proposta dos Institutos Federais, agregar à formação acadêmica a preparação para o trabalho (compreendendo-o em seu sentido histórico, mas sem deixar de afirmar seu sentido ontológico) e discutir os princípios das tecnologias a ele concernentes dão luz a elementos essenciais para a definição de um propósito específico para a estrutura curricular da educação profissional e tecnológica. O que se propõe é uma formação contextualizada, banhada de conhecimentos, princípios e valores que potencializam a ação humana na busca de caminhos de vida mais dignos.

Pacheco ainda registra que um dos objetivos básicos dos Institutos Federais é "derrubar as barreiras entre ensino técnico e científico, articulando trabalho, ciência e cultura". Por isso sua orientação pedagógica deve recusar o conhecimento meramente enciclopédico e buscar uma formação profissional mais abrangente e flexível. O autor ainda destaca que o modelo adotado na Rede IF é inovador, pois apresenta uma proposta diferente "abandonando o hábito de reproduzir modelos externos e ousando inovar a partir de nossas próprias características, experiências e necessidades". (PACHECO, 2011, p. 15).

Todavia, de acordo com Fernandes e Oliveira (2019), é preciso estar atento, pois, apesar de toda esta inovação, o processo de ampliação da Rede IF não deixou de ter apelo populista. A proposta de expansão foi desenhada em 2017, no Plano de Desenvolvimento da Educação - PDE, com previsão de ampliação de $150 \%$ do parque federal de educação profissional e tecnológica em apenas 8 anos. Esta proposta não incluía apenas a expansão estrutural da rede, mas a contratação de pessoal que estava paralisado entre os anos 1995 e 1998.

Tendo ou não pretensão populista, a ampliação da Rede IF representou um enorme diferencial para a população brasileira que precisava se deslocar para a capital para ter acesso a um ensino de qualidade. Aquela educação, que foi criada para os pobres em 1909, voltou a ser acessada pelos pobres, principalmente após a implantação de política de cotas.

Vale destacar, ainda, que "os Institutos Federais deverão ter propostas orçamentárias anuais, identificadas para cada campus e para a reitoria. Isso quer dizer que os recursos orçamentários destinados [...] serão previamente identificados e de acordo com critérios previamente estabelecidos". (VIDOR et al, 2011, p. 94)

A autora deste artigo trabalha em uma cidade com um pouco mais de 10.000 (dez mil) habitantes e a Rede IF oferta educação de qualidade, socialmente referenciada, do ensino médio integrado até a pós-graduação, para, em média, 1.000 estudantes. E alcança todo o 
Vale de Jiquiriçá. Possui Residência Estudantil para os estudantes do ensino médio integrado e Restaurante. Disponibiliza, ainda, Auxílio Moradia para os estudantes dos Cursos Superiores que se encontram em situação de vulnerabilidade social. E, além deste aparato assistencial, os professores, na sua grande maioria, são mestres e doutores, e desenvolvem projetos de pesquisa e extensão com os estudantes.

Existe, no IF Baiano Campus Santa Inês, o desenvolvimento da ciência, da educação, da cultura e do pensamento crítico, porque sua orientação pedagógica recusa o conhecimento enciclopédico e prima pela formação integral. Isto porque ele faz parte de uma rede que articula trabalho, ciência e cultura; uma rede que precisa ser fortalecida, pois impacta positivamente o sistema de ensino brasileiro de forma intensa. Por isso o Brasil precisa emitir um grito coletivo de defesa dessa instituição contra as agressões de setores retrógrados da sociedade, identificados com os valores mais egoístas do capital: "Tira a Mão da Rede IF!".

O capitalismo possui a intenção de colocar em xeque a Educação, e, de modo especial, a Profissional, porque tudo aquilo que se refere ao desenvolvimento da ciência, da cultura e do pensamento crítico fere os princípios capitalistas. Com o intuito de aprofundar este tema, esta seção será subdividida em dois tópicos:

a) O capitalismo: seus estágios e sua especialidade na sociedade brasileira;

b) A educação como política pública que incomoda o capitalismo por formar cidadãos críticos e ser espaço de socialização do conhecimento.

O Capitalismo: seus estágios e sua especificidade na sociedade brasileira

Almeida e Rodrigues (2012) acreditam que pensar a educação nos marcos da sociedade do capital exige refletir sobre seu processo hegemônico, como, também, as possibilidades de resistência e de constituição de outras formas de sociabilidade. Os escritores ainda registram que, para que a educação se torne um direito, livre das artimanhas do capital, é preciso caminhar na direção da construção de uma nova ordem social, ou uma nova perspectiva cultural, algo que se articula com a hegemonia numa escala macro.

Neste caminho, Meszáros (2007) registra que "é necessário romper com a lógica do capital se quisermos contemplar a criação de uma alternativa significativamente diferente ( $p$. 
198). Por sua vez, lasi (2014) lembra que o fundamento da emancipação humana consiste na possibilidade de os homens assumirem o controle da história de forma planejada e consciente.

Todavia, enquanto esta nova hegemonia não se planta, é preciso ter consciência de que a educação também faz parte das contradições que envolvem as lutas sociais por direitos e, por isso, incomoda muito o capitalismo. E a Educação Profissional tem seu espaço de destaque nesta trajetória, principalmente por apresentar um lugar de excelência no desenvolvimento da ciência, da educação, da cultura e do pensamento crítico.

De acordo com Raichelles (2018), o capitalismo do século XXI é mundializado, financeirizado e encontra-se sob a hegemonia neoliberal.

Pacheco (2011, p. 5) ressalta que o neoliberalismo possui um conteúdo ideológico fundado no individualismo e na competitividade que define os princípios da atual sociedade.

Tal ideário e a submissão às normas dos organismos financeiros, representantes dos interesses do capital estrangeiro, construíram a base de um processo de sucateamento e privatização, a preço vil, de grande parte do patrimônio nacional, provocando a vulnerabilidade da economia brasileira.

Ao refletir sobre o neoliberalismo, Lapyda (2011) afirma que, como doutrina política econômica, ele já existe desde a metade do século XX. O autor, que é estudioso de Harvey e de Chesnais, tece algumas observações com base em suas pesquisas:

a) O neoliberalismo envolveu profundas mudanças nas políticas econômica, fiscal e social dos Estados, com a inclusão de flexibilidade do câmbio, cortes de gastos, redução de impostos sobre o capital e grandes riquezas e a elevação da taxa de juros;

b) Outra característica do neoliberalismo é um tipo muito peculiar de fetichismo, ou seja, de ocultamento dos processos sociais. Por exemplo, as privatizações transferiram ativos do domínio público para o privado e apagaram toda a trajetória de construção daquele patrimônio coletivo.

Marques (2018) apresenta como principais características do capitalismo contemporâneo:

a) O capital financeiro ter ocupado o centro das determinações econômicas e sociais; 
b) O capital ter se mundializado de tal forma que o campo da sua acumulação não mais apresenta fronteiras de qualquer ordem. A autora ainda comenta que não interessa ao capital financeiro a manutenção de políticas públicas.

Convém destacar um pouco da revolução do capitalismo para a compreensão dos seus ditames na atualidade. De acordo com Netto e Braz (2008, p. 169),

Ao longo de sua existência, o capitalismo moveu-se (move-se) e transformou-se (transforma-se); mobilidade e transformação estão sempre presentes nele: mobilidade e transformação constituem o capitalismo, graças ao rápido e intenso desenvolvimento de forças produtivas que é a sua marca.

Segundo os autores, o estágio inicial do capitalismo é o comercial ou mercantil (Século XVI a meados do Século XVIII). Nesta fase, os comerciantes e mercadores tiveram destaque. A burguesia "afirma-se como classe que tem nas mãos o controle das principais atividades econômicas e confronta-se com os privilégios da nobreza fundiária" (NETO; BRAZ, 2008, p.170).

Já no segundo estágio (que teve início da segunda metade do século XVIII e foi até o último terço do século XIX), afirmam os autores que ocorre o capitalismo concorrencial (também denominado de liberal ou clássico). "Sobre a base da grande Indústria (a indústria moderna), que provocará um processo de urbanização sem precedentes, o capitalismo concorrencial criará o mercado mundial". (NETO; BRAZ, 2008, p.172). É nesse período que as lutas de classes, de acordo com os autores, aparecem na modalidade moderna: fundadas na contradição capital versus trabalho.

O terceiro e atual estágio (últimas três décadas do século XIX e presente até os dias atuais) é apresentado pelos autores como imperialista e tem como especificidade o papel decisivo do capital financeiro. Neste estágio aparecem três fases:

a) Fase clássica (mais ou menos de 1890 a 1940);

b) Anos dourados (do fim da Segunda Guerra Mundial até a entrada dos anos 70), marcado pela presença do Estado na regulação econômica e social;

c) Contemporânea (de meados dos anos 70 aos dias atuais).

Os autores ainda ressaltam que

O capitalismo contemporâneo particulariza-se pelo fato de, nele, o capital estar destruindo as regulamentações que foram impostas como resultado das lutas do movimento operário e das camadas trabalhadoras [...]. Para legitimar essa estratégia, o grande capital fomentou e patrocinou a divulgação maciça do conjunto ideológico que se difundiu sob a designação de neoliberalismo [...] a ideologia neoliberal, sustentando a necessidade de "diminuir" o Estado e cortar suas "gorduras", justifica o ataque que o grande 
capital vem movendo contra as dimensões democráticas da intervenção do Estado na economia. (NETO; BRAZ, 2008, p. 225-227).

Harvey chega a afirmar que faz parte da produção capitalista a especulação, porém, dentro do "sistema financeiro essa característica é exacerbada, transformando-se em fetiche supremo. Os financistas, diz Marx, possuem o agradável caráter hibrido de vigaristas e profetas" (HARVEY, 2018, p. 49).

Ao se reportar à sociedade brasileira, Fernandes (1975) considera terem existido três fases no desenvolvimento capitalista:

a) Fase de eclosão de um mercado capitalista especificamente moderno, que consiste, na verdade, em uma fase de transição neocolonial (vai da abertura dos portos até a sexta década do século XIX);

b) Fase de formação e expansão do capitalismo competitivo, que se caracteriza pela consolidação e disseminação desse mercado e por seu funcionamento como fator de diferenciação do sistema econômico (vai da sexta década do século XIX até a década de 50 do século XX);

c) Fase de irrupção do capitalismo monopolista, que apresentou um quadro histórico profundamente diverso do da escala mundial.

Fernandes explica que "a economia brasileira se relacionou com a expansão do capitalismo monopolista segundo a forma típica que ela assumiu com referência à parte mais pobre, dependente e subdesenvolvida da periferia" (FERNANDES, 1975, p. 255). Para o sociólogo e educador, é sob o capitalismo monopolista que o desenvolvimento desigual da periferia se torna mais perverso.

Nessa direção, Almeida (2019, p. 173), destaca que:

O Brasil, historicamente, se inscreveu na dinâmica do capitalismo mundial de forma subordinada, de forma periférica, lidando com os desafios do processo de acumulação do capital a partir da mediação de interesses que são próprios e particulares da burguesia no Brasil - que também tem a necessidade imperiosa de valorizar seu capital -, mas o faz de forma integrada e subordinada aos interesses do grande capital internacional.

Ainda conforme Almeida (2019), o Brasil adotou, em relação à Política de Educação, traços que são próprios de um país periférico e dependente, onde o direito à educação não foi ainda plenamente universalizado e quando é acessado requer algum apoio assistencial devido à situação de vulnerabilidade social da população. Isto porque, em uma sociedade 
como a brasileira, onde as desigualdades são acentuadas, de acordo com Fernandes (1975), apesar de ter se livrado da condição legal de colônia, continuou na condição de sujeição à vontade econômica externa.

Partilhando deste pensamento, Martins e Almeida (2019) ressaltam que a educação como política pública vem sendo construída em um palco de disputas de projetos antagônicos. As atuais reformas educacionais têm procurado modificar radicalmente a educação, tornando-a mais instrumental e mercadológica, visando ao "novo perfil de trabalhador exigido pelo capital, deslocando o foco de uma formação integral para uma formação funcional a essa sociabilidade capitalista" (p.1-2).

De modo que, a estratégia do Estado, impregnado pelo receituário neoliberal é transformar a educação em um "nicho de mercado" realizando cortes de orçamento público e fortalecendo o apelo à iniciativa privada para garantir a necessária formação profissional prática instrumental. MARTINS; ALMEIDA, 2019, p. 2).

Sendo assim, Santos et al (2019, p. 15) registram que são muitas "as determinações e mediações que permitem apreender e decifrar a realidade do Brasil contemporâneo imposta pelas classes dominantes e seu modo de ser nos dias atuais: furioso, conservador e antidemocrático". E esta fúria é bem ressaltada na forma de ataque à educação.

Convém registrar as observações de Roberto Leher (2018, p. 33), que afirma: "empresas que compõem o rol dos 200 maiores grupos econômicos com atuação no Brasil interferem diretamente na educação básica, profissional e superior".

Voltando a Almeida (2019), o processo de ampliação do acesso à educação superior, apesar de ter assegurado o ingresso de novos segmentos sociais ao ensino universitário, ocorreu de forma subordinada aos processos de grande mercantilização da vida social. Sendo assim, parte do fundo público vem sendo destinada para: Programa Universidade para Todos (PROUNI) e Programa de Financiamento Estudantil (FIES). Estes se tornaram uma das principais fontes de expansão de enormes conglomerados educacionais como a Kroton e a Estácio de Sá, que além disto, recebem apoio financeiro do Banco Nacional de Desenvolvimento Econômico e Social (BNDES) na ampliação das suas aquisições de expansão.

E Leher deixa claro que, apesar e por causa das lutas sociais, a situação é bastante contraditória: 
Resultantes também da pressão social em prol da democratização do acesso à educação superior, as cotas, o ENEM - Exame Nacional do Ensino Médio , o ProUni e o FIES, contraditoriamente, foram a tábua de salvação da grande mercantilização da educação no Brasil liderada pelas frações burguesas vinculadas às finanças por meio de fundos de investimentos [...] A adoção de políticas de ação afirmativa e o financiamento estudantil possibilitaram, em nome da democratização, ampliar o mercado educacional e favoreceram como nunca as corporações (LEHER, 2018, p. 47-48).

Neste sentido, Salvador (2019) esclarece que o fundo público abraça a capacidade de mobilização de recursos que o Estado possui para intervir na economia e uma das primordiais formas de realização deste fundo ocorre pela extração de recursos da sociedade por meio de impostos, contribuições e taxas.

O entendimento do processo de constituição e alocação do fundo público não é um movimento alheio ao cotidiano dos indivíduos, do direito à cidade, à educação e ao trabalho. Ao contrário, mediante os caminhos tortuosos trilhados pelo Estado para assegurar a proteção para o capital passar, descortinamos mediações e localizamos que o que está em jogo é, simultaneamente a captura do fundo público pelo capital no contexto do ajuste fiscal permanente e da contrarreforma do Estado Brasileiro. (SANTOS et al, 2019, p. 14).

lamamoto (2018, p. 75) esclarece que "o bloco dominante vem seccionando o orçamento público em favor das finanças, de interesses particulares das várias frações do capital e dos proprietários fundiários, surdo aos clamores da maioria".

E a autora vai mais além ao afirmar que

O fundo público, majoritariamente direcionado aos interesses do capital que rende juros, tem parcela significativa capturada pela corrupção que grassa nos centros do poder em aliança com segmentos do grande empresariado, em detrimento das políticas e serviços públicos universais e de qualidade. Este quadro apoia-se no braço repressivo e judicial do Estado e na radicalização da violência oficial (IAMAMOTO, 2018, p. 75).

Isto tudo justifica a necessidade de o capitalismo colocar em xeque a Educação, e, de modo especial, a Profissional. Ela incomoda porque ela forma cidadãos críticos e é espaço de produção e socialização do conhecimento. No Brasil dos últimos anos, o capital e seus governos procuram massificar a ideia de que a educação profissional é muito dispendiosa, gerando a necessidade de desqualificar essa formação. Nesta perspectiva, acredita-se que são os movimentos sociais da educação os sujeitos que, parafraseando Dante Moura (2013), 
vão plantar e cuidar para que cresçam as sementes da educação profissional pública e de qualidade. Mas para isso será preciso saber aproveitar as contradições do sistema capitalista.

Um dos ataques recentes à Educação Profissional foi o corte de quase 50\% na verba da Assistência Estudantil. O impacto disso nos 15 campi do IF Baiano foi muito difícil. Uma escola cuja grande maioria dos estudantes vive em situação de vulnerabilidade social precisa de uma Política consistente de Assistência Estudantil. No entanto, como Salvador (2019, p. 104) ressalta: "a característica comum a todas as crises do capital nos últimos 30 anos é o comparecimento do fundo público para socorrer instituições financeiras falidas durante as crises bancárias, à custa dos impostos pagos pelos cidadãos". Ou seja, o esquema é retirar recursos da educação pública para investir na educação privada (no capital).

Salvador (2019, p. 107) ainda relata que, com o Golpe de 2016 e o governo Temer, ocorreu uma intensificação da ofensiva do capital, "voltando com carga à ortodoxia neoliberal com brutal corte de direitos sociais, sobretudo, no campo do financiamento público". E a educação tem sido alvo preferencial deste desmonte.

Trata-se de colocar em xeque a existência e a funcionalidade da universidade pública e dos institutos federais como espaços de produção e socialização do conhecimento, de formação profissional e humana da juventude, e a ideia é esta mesma, aniquilar o desenvolvimento da ciência, da educação, da cultura e do pensamento crítico. (SANTOS et al, 2019, p. 16)

Compactuando com esta ideia, Neri e Vilela (2017) explicam que a reforma do ensino médio, a emenda do teto dos gastos, as recentes investidas da Justiça e da Polícia Federal contra Universidades e Institutos Federais representam a prova explícita de que a Rede Federal de Educação está sob um forte ataque. Inclusive esses elementos se entrelaçam em uma trama que objetiva à mercadorização da Educação no Brasil.

Neri e Vilela (2017) entendem a mercadorização como o processo pelo qual a educação brasileira está se transformando em uma mercadoria padronizada, de conteúdo pobre e métodos simples e diretos de comercialização. Eles lembram que o investimento público no ensino privado foi impulsionado nos governos $\mathrm{FHC}$, através do BNDES, e foi ampliado nos governos Lula e Dilma, por meio do FIES e do PROUNI. Além disto, com a reforma do ensino médio, uma linha de ação visa permitir que toda a educação brasileira seja pacificamente entregue aos gigantes do ensino privado. 
Por isso afirmamos que a Rede Federal de Educação é a Nova Petrobras. Ela é alvo dos grandes grupos que controlam o ensino privado, que querem abocanhar parte significativa do orçamento destinado ao ensino básico, oferecendo serviços de baixa qualidade e elevadas taxas de lucro (NERI; VILELA, 2017. p. 5)

E é isto exatamente o que o capitalismo pretende fazer, abocanhar literalmente o orçamento destinado aos Institutos e Universidades Federais. Mas, por que a Rede Federal de Educação Profissional incomoda tanto ao capital? A resposta é óbvia: por representar um projeto de ensino diferenciado, voltado ao desenvolvimento da ciência, da cultura e do pensamento crítico e acessível às camadas mais pobres da população.

Neste sentido, Santos et al (2019) ressaltam que o mais difícil da luta é discernir o lado em que se deve lutar e saber claramente em que lado se está; ademais, as lutas sociais precisam ser enraizadas e agigantar-se no cotidiano da classe trabalhadora. Então, as palavras do momento devem ser resistência, por meio de organização de fóruns e espaços coletivos, e insistência no desenvolvimento de pesquisas e produção crítica do conhecimento.

Na Palestra de abertura do Seminário "Tira a Mão do Nosso IF", ministrada pelo Prof. Dr. Penildon Silva Filho, intitulada "Os Institutos e as Universidades Federais no contexto da 'balburdia': desafios e resistências", que ocorreu no dia 12 de setembro de 2019, algumas observações foram destacadas pelo preletor e, por sua relevância, precisam ser aqui especificadas:

O atual ataque à educação é sistêmico e global, por isso a resistência/mobilização também precisam ser globais; a estratégia de privatização da educação não é algo isolado. Faz parte de uma proposta internacional. O Governo Bolsonaro representa a fase avançada de um golpe que vem se estendendo há anos; é importante ressaltar que quando o capital entra em crise ele aumenta a exploração para sair da crise. Ele retira direitos e reforça a repressão política. E por ser o capitalismo do Brasil periférico isto é realizado de forma mais acentuada ainda. (SINASEFE IFBA, 2019, p. 1)

Diante do exposto, só resta à comunidade acadêmica da Rede IF resistir e insistir. Estudantes e seus familiares, professores, servidores técnicos administrativos precisam estar unidos neste processo de resistência e insistência, de luta coletiva pela Rede IF de Educação Profissional e Tecnologia, que foi criada para os pobres, mas que nunca se permitiu ser pobre, ofertando um ensino de qualidade socialmente referenciado. O Brasil precisa se unir e entoar um grito único: "Tira a Mão da Rede IF!". 


\section{Considerações finais}

RESISTIR, verbo que se conjuga sempre no coletivo, mobilizando o pensamento crítico, construtivo, criativo em busca de estratégias de luta na direção de "uma outra sociabilidade" e resgatando a importância, nem messiânica e nem fatalista da Educação. (MARTINS; ALMEIDA, 2019, p. 4).

Assim, o verbo do momento para a Educação Profissional é Resistir: 1. Aos ataques do capitalismo; 2. Aos despropósitos do Governo Bolsonaro; 3. À insuficiente mobilização da comunidade acadêmica, incluindo estudantes, professores e servidores técnicoadministrativos.

Já ficou bem claro, na exposição, que a desmobilização é uma estratégia do neoliberalismo, mas o momento é de enraizar e agigantar as lutas sociais, pois a malignidade do capital precisa de um basta.

O artigo procurou demonstrar a vontade do capitalismo de colocar em xeque a Educação, e, de modo especial, a Profissional, porque ela incomoda por formar cidadãos críticos e ser um espaço de produção e socialização do conhecimento. E que é intenção do capitalismo abocanhar o orçamento destinado ao ensino público em geral.

Mas o verbo Resistir necessita do acompanhamento de outro verbo: Insistir:

a) Em provar que o capitalismo é perverso e que a Educação Profissional é resultado de uma conquista social inovadora;

b) Em mostrar que o Governo Bolsonaro é resultado da alienação de um povo que se deixou cooptar por um mito pérfido postado no altar do imperialismo;

c) Em acreditar que os movimentos sociais da educação poderão fazer diferença se desenvolverem agendas organizadas de análise de conjuntura e de orientação da população brasileira quanto ao que está por trás dos ataques à educação.

E se Resistir é mobilizar o pensamento crítico, construtivo e criativo; Insistir é acreditar que este pensamento crítico, construtivo e criativo será capaz de enfrentar os ditames do capitalismo na contemporaneidade. 


\section{Referências}

ALMEIDA, Ney Luis Teixeira de; RODRIGUES, Maria Cistina Paulo. O Campo da Educação na Formação Profissional em Serviço Social. In: PEREIRA, Larissa Dahmer; ALMEIDA, Ney Luiz Teixeira de (Org.). Serviço Social e Educação. 2. ed. Rio de Janeiro: Ed. Lumen Juris; Rio de Janeiro, 2012.

ALMEIDA, Ney Luis Teixeira de Almeida. A Política de Educação no Brasil no Contexto de Superexploração da Força de Trabalho. In: MARTINS, Eliana Bolorino Canteiro; ALMEIDA, Ney Luis Teixeira de. I Seminário Internacional de Serviço Social na Educação e V Fórum de Serviço Social na Educação: Educação e Serviço Social no Contexto de Crise do Capital. Franca: UNESP - FCHS, 2019. E-book.

ANJOS, Nívia Barreto dos. O Lugar da Educação Profissional na Garantia do Direito. Revista Brasileira de Educação Profissional e Tecnológica, Natal, v.1, n. 18, jan.- jun.2020.

BRASIL. Lei no 11.892, de 29 de dezembro de 2008. Institui a rede Federal de Educação Profissional, Científica e Tecnológica, cria os Institutos federais de Educação, Ciência e Tecnologia e dá outras providências. Diário Oficial da União, Brasília, 30 dezembro de 2008.

CALDAS, Luiz. A Formação de Professores e a Capacitação de Trabalhadores da EPT. In: PACHECO, Eliezer (Org). Institutos Federais Uma Revolução na Educação Profissional e Tecnológica.

Brasília: Fundação Santillana; São Paulo: Editora Moderna, 2011.

FERNANDES, Florestan. A Revolução Burguesa no Brasil: ensaio de Interpretação Sociológica. Rio de Janeiro: Zahar Editores, 1975.

FERNANDES, Lígia da Nóbrega; OLIVEIRA, Cirlene Aparecida Hilário da Silva. Indicativos da Precarização do Trabalho de Assistentes Sociais nos IFET'S a partir dos Revesses do Mundo do Trabalho. In: MARTINS, Eliana Bolorino Canteiro e ALMEIDA, Ney Luis Teixeira de. I Seminário Internacional de Serviço Social na Educação e V Fórum de Serviço Social na Educação: "Educação e Serviço Social no Contexto de Crise do Capital". Franca: UNESP - FCHS, 2019. E-Book.

HARVEY, David. A Loucura da Razão Econômica: Marx e o capital do século XXI. Trad. de Artur Renzo. São Paulo: Boitempo, 2018.

IAMAMOTO, Marilda Villela. Serviço Social, "questão social" e trabalho em tempo de capital fetiche. In: RAICHELIS, Raquel; VICENTE, Damares; ALBUQUEROUE, Valéria. (Org.). A Nova Morfologia do Trabalho no Serviço Social. São Paulo: Cortez, 2018.

IASI, Mauro. As Manifestações de massa e a dimensão estratégica. In: ABRAMIDES, Maria Beatriz; DURIGUETTO, Maria Lucia (Org.). Movimentos Sociais e Serviço Social: uma relação necessária. São Paulo: Cortez, 2014.

LAPYDA, Ilan. A "financeirização" no capitalismo contemporâneo: uma discussão das teorias de François Chesnais e David Harvey. 2011. 223 f. Dissertação (Mestrado em Sociologia) - Faculdade de Filosofia, Letras e Ciências Humanas, Universidade de São Paulo, São Paulo, 2011.

doi:10.11606/D.8.2011.tde-30092011-095732.

LEHER, Roberto. Universidade e Heteronomia Cultural no Capitalista Dependente: um estudo a partir de Florestan Fernandes. Rio de Janeiro: Consequência, 2018 
MARQUES, Rosa Maria. O capitalismo financeiro e as políticas sociais: a nova face da contemporaneidade. In: RAICHELIS, Raquel; VICENTE, Damares; ALBUQUERQUE, Valéria. (Org.). A Nova Morfologia do Trabalho no Serviço Social. São Paulo: Cortez, 2018.

MARTINS, Eliana Bolorino Canteiro e ALMEIDA, Ney Luis Teixeira de. Apresentação. In: MARTINS, Eliana Bolorino Canteiro e ALMEIDA, Ney Luis Teixeira de. I Seminário Internacional de Serviço Social na Educação e V Fórum de Serviço Social na Educação: "Educação e Serviço Social no Contexto de Crise do Capital". Franca: UNESP - FCHS, 2019. E-Book.

MESZÁROS, István. O Desafio e o Fardo do Tempo Histórico. São Paulo: Boitempo, 2007.

MOURA, Dante Henrique. Ensino Médio Integrado: subsunção aos interesses do capital ou travessia para a formação humana integral? Educ. Pesqui., São Paulo, v.39, n.3, p. 705-720, jul.set., 2013 .

NERI, Daniel e VILELA, Elenira. A Rede Federal de Educação é a Nova Petrobrás. In: GGN - O Jornal de Todos os Brasis, [s.I.], 21 dez. 2017.

NETTO, José Paulo e Braz, Marcelo. Economia Política: uma introdução crítica. 4. ed. São Paulo: Cortez, 2008 (Biblioteca Básica do Serviço Social, v. 1)

PACHECO, Eliezer. Apresentação. In: PACHECO, Eliezer (Org.). Institutos Federais Uma Revolução na Educação Profissional e Tecnológica. Brasília: Fundação Santillana; São Paulo: Editora Moderna, 2011.

PACHECO, Eliezer. Institutos Federais: uma revolução uma revolução da educação profissional e recnológica. In: PACHECO, Eliezer (Org.). Institutos Federais Uma Revolução na Educação Profissional e Tecnológica. Brasília: Fundação Santillana; São Paulo: Editora Moderna, 2011.

RAICHELIS, Raquel. Serviço Social: trabalho e profissão na trama do capitalismo contemporâneo. In: RAICHELIS, Raquel; VICENTE, Damares; ALBUQUEROUE, Valéria. (Org.). A Nova Morfologia do Trabalho no Serviço Social. São Paulo: Cortez, 2018.

SANTOS, Silvana Mara de Morais dos. SALVADOR, Evilásio; BEHRING, Elaine; LIMA, Rita de Lourdes de. Introdução. In: SALVADOR, Evilásio; BEHRING, Elaine; LIMA, Rita de Lourdes de (Org.). Crise do Capital e Fundo Público: implicações para o trabalho, os direitos e a política social. São Paulo: Cortez, 2019.

SALVADOR, Evilásio. Fundo Público, Crise e Financeirização da Previdência Social. In: SALVADOR, Evilásio; BEHRING, Elaine; LIMA, Rita de Lourdes de (Org.). Crise do Capital e Fundo Público: implicações para o trabalho, os direitos e a política social. São Paulo: Cortez, 2019.

SINASEFE - IFBA. Seminário Tire a Mão do Nosso IF: diálogos sobre Educação Profissional e Tecnológica. Palestra de Abertura com Prof. Dr. Penilson Silva Filho. 2019.

TRIVIÑOS, Augusto N. S. Introdução à Pesquisa em Ciências: A pesquisa qualitativa em educação. São Paulo: Atlas, 1987.

VIDOR, Alexandre; REZENDE, Caetana; PACHECO, Eliezer; CALDAS, Luiz. Institutos Federais: Lei no 11.892 de 29/12/2008 - Comentários e reflexões. In: PACHECO, Eliezer (Org.). Institutos 
Federais Uma Revolução na Educação Profissional e Tecnológica. Brasília: Fundação Santillana; São Paulo: Editora Moderna, 2011.

\section{Dados da autora}

Nívia Barreto dos Anjos

Assistente Social do Instituto Federal de Educação Ciência e Tecnologia Baiano (Campus de Santa Inês, Bahia) e mestre em Políticas Sociais e Cidadania pela Universidade Católica do Salvador (UCSal). E-mail: niviabfc@hotmail.com ORCIDiD https://orcid.org/0000-0002-4225-9868. 